\title{
FORMULASI STRATEGI PENGEMBANGAN BISNIS SALON XYZ
}

\section{STRATEGY FORMULATION OF BUSINESS DEVELOPMENT AT SALON XYZ}

\author{
Nawangwulan Ratri Dewi*1, Sukardi ${ }^{* * *}$, dan Setiadi Djohar ${ }^{* * * *}$ \\ *) Sekolah Bisnis, Institut Pertanian Bogor \\ Jl. Raya Pajajaran, Bogor 16151 \\ **) Departemen Teknologi Industri Pertanian, Fakultas Teknologi Pertanian, Institut Pertanian Bogor \\ Gedung Fateta Lantai 2, Kampus IPB Dramaga Bogor 16680 \\ ${ }^{* * *}$ Sekolah Tinggi Manajemen PPM \\ Jl. Menteng Raya No. 9-19, DKI Jakarta 10340
}

\begin{abstract}
One type of service business that has increased rapidly is the beauty salon business. Big cities are supporters of the growth of salon businesses, such as the city of Bogor. One salon in the city of Bogor that is quite developed is the XYZ Salon. Following its success, XYZ Salon wanted to develop a salon business outside the city of Bogor. The purpose of this study are 1) to describe the business process of XYZ Salon; 2) identifying strengths, weaknesses, opportunities and threats for the XYZ Salon; 3) formulate alternative business development strategies outside the city of Bogor; 4) choose the priority strategy that can be used in the development of the XYZ Salon business. The methods used in this study are: 1) identification of the XYZ Salon business process by using descriptive analysis; 2) identification of XYZ Salon internal factors using the Internal Factor Evaluation (IFE) method and identification of the XYZ Salon external factors using the External Factor Evaluation (EFE) method, positioning the XYZ Salon business using the Internal External (IE) matrix; 3) alternative strategy formulations using the SWOT matrix method; 4) formulating priority strategies with the Quantitative Stratategy Planning Matrix (QSPM) method. The results of internal and external analysis found that the position of XYZ Salon is in quadrant II, namely in the position of growing and building, the strategy that must be done is market expansion, product expansion and product penetration. The results of the alternative SWOT matrix strategy obtained a priority strategy from QSPM is to expand market share by opening outlets outside the city of Bogor, namely to Jakarta, Depok, Bandung and Bekasi.
\end{abstract}

Keywords: EFE, salon business, IFE, QSPM, SWOT

\begin{abstract}
Abstrak: Salah satu jenis usaha jasa yang mengalami peningkatan dengan pesat adalah usaha salon kecantikan. Kota besar menjadi pendukung tumbuhnya usaha salon, seperti kota Bogor. Salah satu salon di kota Bogor yang cukup berkembang adalah Salon XYZ. Menyusul keberhasilannya, Salon XYZ ingin mengembangkan bisnis salon ke luar kota Bogor. Tujuan dari penelitian ini adalah 1) mendeskripsikan proses bisnis Salon XYZ; 2) mengidentifikasi kekuatan, kelemahan, peluang dan ancaman bagi Salon XYZ; 3) memformulasikan alternatif strategi pengembangan bisnis di luar kota Bogor; 4) memilih prioritas strategi yang dapat digunakan dalam pengembangan bisnis Salon XYZ. Metode yang digunakan pada penelitian ini adalah: 1) identifikasi proses bisnis Salon XYZ dengan menggunakan analisis deskriptif; 2) identifikasi faktor internal Salon XYZ menggunakan metode Internal Factor Evaluation (IFE) dan identifikasi faktor eksternal Salon XYZ menggunakan metode External Factor Evaluation (EFE), penentuan posisi bisnis Salon XYZ dengan menggunakan matriks Internal External (IE); 3) formulasi alternatif strategi menggunakan metode matriks SWOT; 4) perumusan strategi prioritas dengan metode Quantitative Stratategy Planning Matrix (QSPM). Hasil analisis internal dan eksternal didapatkan posisi Salon XYZ berada pada kuadran II yaitu pada posisi bertumbuh dan membangun, strategi yang harus dilakukan adalah perluasan pasar, perluasan produk dan penetrasi produk. Hasil dari alternatif strategi matriks SWOT, didapatkan prioritas strategi dari QSPM adalah memperluas pangsa pasar dengan membuka outlet di luar kota Bogor yaitu ke Jakarta, Depok, Bandung dan Bekasi.
\end{abstract}

Kata kunci: EFE, bisnis salon, IFE, QSPM, SWOT

\footnotetext{
${ }^{1}$ Alamat Korespondensi:

Email: nawangjacoeb@gmail.com
} 


\section{PENDAHULUAN}

Dunia bisnis saat ini mengalami perkembangan yang sangat pesat. Kondisi ini menjadikan ramainya persaingan usaha. Dengan laju pertumbuhan penduduk $1,49 \%$ per tahun dengan perkiraan jumlah penduduk sebanyak 255 ribu juta pada tahun 2015, menjadikan Indonesia merupakan pasar potensial untuk semua produk (Rurkinantia et al. 2017).Tingginya kesibukan para wanita di kota besar seperti berkembangnya kelompok wanita yang bekerja serta didasari kebutuhan lahiriah seorang wanita yang selalu ingin tampil cantik dan sempurna dalam berbagai keadaan, menjadi pendorong bisnis salon untuk terus berkembang karena memiliki pasar yang terus bertambah. Winarno dan Agustinah (2007) menyebutkan $85 \%$ penyakit manusia berakar dari keadaan stress, maka terapi di salon yang melalui konsep pemijatan dan relaksasi diperlukan sebagai terapi pencegahan dan pengobatan bagi mereka yang tingkat mobilitasnya tinggi. Selain itu, terapi spa bermanfaat dalam mengobati penyakit punggung dan arhritis yang kerap kali dialami oleh para wanita yang sibuk (Klick dan Strattman, 2008).

Jumlah pelaku bisnis salon setiap tahunnya mengalami peningkatan. Hasil riset yang dilakukan PT L'Oreal menyebutkan penambahan jumlah bisnis bidang ini mencapai $10 \%$ setiap tahun. Jumlah pelaku usaha salon hingga 2012 yang tersebar di Indonesia mencapai 90 ribu usaha (Kompas, 2012). Melihat kondisi ini menyebabkan para pengusaha salon dituntut untuk mempunyaistrategiyang tepat. Tantangan bisnisindustri salon adalah menciptakan keunikan dan kekhususan yang berorientasi pada customer requirement sebagai keunggulan bersaing yang berkelanjutan (Widjaja 2009). Karnelly (2010) menyatakan kepuasankonsumen terletak pada keunikan dan keunggulan perusahaan.

Kota besar menjadi salah satu pendukung pertumbuhan sektor jasa salon. Kota Bogor merupakan kota wisata dan kota pendidikan yang memiliki potensi dalam peningkatan mobilitas wanita, baik yang bekerja ataupun yang mengenyam pendidikan tinggi. Dengan jumlah penduduk sebanyak 1.064.687 yang terdiri dari 540.288 penduduk pria dan 524.399 penduduk wanita (BAPPEDA, 2017). Sebanyak 48,86\% jumlah wanita yang bekerja (BPS, 2005). Tingginya populasi wanita di kota Bogor merupakan target yang baik untuk bisnis jasa salon. Sampai dengan tahun 2017 terdapat sekitar 100 salon di kota Bogor. Salah satu salon di Bogor adalah Salon XYZ yang mempunyai11 cabang di kota Bogor. Perusahaan berencana memperluas usaha ke luar kota karena banyak konsumen Salon XYZ berasal dari luar kota. Keberhasilan Salon XYZ dalam mengembangkan usaha membuat pengusaha lain mendirikan usaha sejenis, itu terlihat dari banyaknya salon yang dibangun di kota Bogor. Pertumbuhan salon lain membuat persaingan usaha salon di kota Bogor semakin ketat. Dengan datangnya banyak pesaing baru membawa dampak yang kurang baik bagi kelangsungan bisnis Salon XYZ. Pada tahun 2017 jumlah turn over karyawan lebih dari $25 \%$. Salah satu penyebab turn over karena banyak karyawan yang dibajak oleh kompetitor sehingga mengganggu operasional perusahaan. Dampak lain yang terjadi adalah tren kenaikan pendapatan Salon XYZ menurun. Bisa dilihat pada Gambar 1 periode tahun 2016-2017 Salon XYZ mengalami penurunan kenaikan omzet yang berbanding lurus dengan penurunan laba yang didapatkan perusahaan. Penurunan ini perlu dievaluasi agar tidak membawa dampak buruk bagi para stakeholder.

Pada kondisi pasar yang kompetitif perusahaan harus memiliki pemahaman yang menyeluruh mengenai kondisi internal dan eksternal perusahaanya untuk menentukan suatu strategi yang tepat (Xia Chan, 2011). Komaryatin (2007) dan Kurniawati dan Sari (2009) menyebutkan bahwasetiap perusahaan seharusnya dapat melihat jauh kedepan dalam mengembangkan strategi untuk mengantisipasi kondisi persaingan yang semakin ketat.Faktor internal maupun eksternal merupakan faktor-faktor penting yang memengaruhi perusahaan dalam menjalankan bisnisnya dan dapat menghasilkan alternatif strategi (Mitrady et al. 2015). Melihat kondisi perusahaan, formulasi strategi dibutuhkan untuk dapat berkembang. Dalam menyelesaikan isu-isu strategis yang muncul, strategi utama sangat berkaitan dengan strategi-strategi pendukung seperti meningkatkan kualitas SDM, memanfaatkan investor, sosialisasi kepada masyarakat, mengoptimalkan keterkaitan visi, misi dan tujuan organisasi, serta meningkatkan kualitas perencanaan dan penganggaran (Zuhaidha, 2014). Pendidikan dan pelatihan dapat memengaruhi kinerja karyawan dalam mencapai tujuan dari perusahaan dalam menciptakan keunggulan kompetitif (Turere, 2013). Pengembangan kapasitas SDM terhadap karyawan juga berimplikasi terhadap perencanaan strategik perusahaan kedepan (Hutahaen et al. 2017). Tabassi et al. (2012) menyatakan bahwa pelatihan berpengaruh signifikan terhadap motivasi. Motivasi 
kerja merupakan keinginan yang menggerakkan diri karyawan untuk bekerja dengan baik dan mencapai tujuan tertentu. Motivasi merupakan bagian yang sangat penting dari produktivitas kinerja karyawan (Nawab et al. 2011).

Perusahaan yang mampu bertahan hidup harus dapat juga memperoleh laba jangka panjang, memperoleh laba sehingga perusahaan akan dapat tumbuh dan berkembang (Tantra, 2015). Dalam memformulasikan strategi yang tepat, dibutuhkan beberapa tahapan yang harus dilalui, antara lain analisis situasi, formulasi strategi, implementasi strategi, dan evaluasi strategi (Coulter, 2005). Hidayat (2012) menyebutkan bahwa untuk mengelola bisnis jasa, strategi yang dapat dilakukan diantaranya adalah strategi penetrasi pasar, pengembangan produk, pengembangan pasar, dan diversifikasi.

Tujuan Penelitian adalah Mendeskripsikan proses bisnis Salon XYZ; Mengidentifikasi kekuatan, kelemahan, peluang dan ancaman bagi Salon XYZ; Memformulasikan alternatif strategi pengembangan bisnis di luar kota Bogor; Memilih prioritas strategi yang dapat digunakan oleh Salon XYZ.

Penelitian ini difokuskan pada pengkajian tentang pengembangan bisnis di luar kota Bogor. Meliputi pengkajian dan analisis proses bisnis, melakukan observasi kondisi internal dan eksternal Salon XYZ, memformulasikan alternatif strategi dan memprioritaskan alternatif strategi bagi pengembangan Salon XYZ yang sesuai dengan posisi bisnis perusahaan agar dapat menjadi pertimbangan perusahaan.

\section{METODE PENELITIAN}

Penelitian ini dilaksanakan di salah satu salon di Kota Bogor yaitu Salon XYZ. Penelitian dilakukan di 12 tempat. Kantor pusat Salon XYZ yang beralamat di Jalan Bangbarung Raya No. 40, di Kota Bogor, Jawa Barat dan di 11 outlet Salon XYZ. Pengambilan data dilakukan sejak Desember 2017 sampai dengan Januari 2018. Metode pengambilan sampel dalam penelitian ini adalah purposive sampling.

Kajian ini menggunakan data primer dan data sekunder yang bersifat kualitatif. Sumber data primer di dapat dari internal dan eksternal perusahaan. Sumber internal diperoleh dari pemilik dan karyawan Salon XYZ. Adapun sumber eksternal berasal dari konsumen Salon XYZ. Responden dimintai tanggapannya melalui kuesioner dan wawancara. Pengumpulan data dan informasi yang diperlukan pada penelitian ini dilakukan melalui berbagai cara, yaitu sebagai berikut:

1. Studipustaka, dilakukan dengan membaca dokumendokumen pendukung meliputi jurnal ilmiah, skripsi, tesis, disertasi, artikel, serta dokumen-dokumen pendukung lainnya yang berhubungan dengan penulisan tesis ini. Studi pustaka dilakukan untuk mempelajari konsep formulasi pengembangan bisnis.

2. Observasi lapangan, dilakukan dengan mengamati secara langsung kegiatan-kegiatan yang dilakukan terkait bisnis Salon XYZ. Observasi dilakukan dengan cara terjun langsung ke lapangan agar peneliti lebih mengenal aktivitas perusahaan.

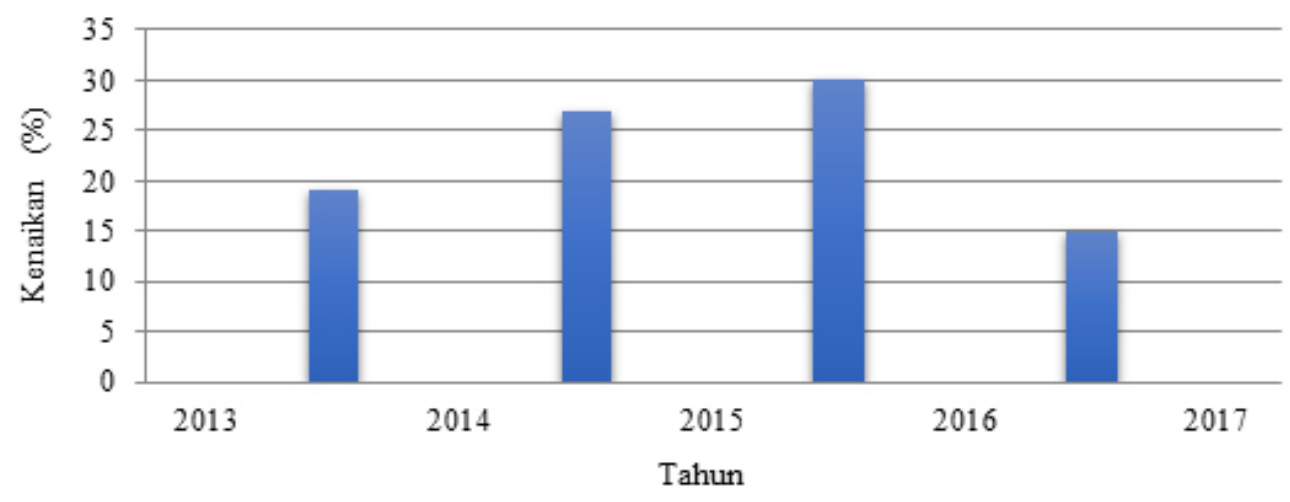

Gambar 1. Grafik presentase omzet salon XYZ Tahun 2013-2017 
3. Wawancara, dilakukan terhadap orang-orang yang memegang peranan dalam aktivitas bisnis Salon XYZ. Wawancara ini dilakukan untuk memperoleh informasi-informasi terkait matriks kinerja yang diukur. Wawancara digunakan untuk memperluas cakrawala peneliti tentang data lain yang tidak terformulasi dalam kuesioner. Namun, akan memiliki implikasi strategis bagi perusahaan sehingga layak untuk dilakukan penelitian lebih lanjut. Selain itu wawancara juga digunakan untuk melengkapi data terkumpul melalui kuesioner (Soesatyo dan Rumambi, 2013). Wawancara dilakukan dengan pihak eksternal dan pihak internal. Dari pihak eksternal wawancara dilakukan dengan 3 konsumen Salon XYZ, dan dari pihak manajemen Salon XYZ, dilakukan wawancara dengan owner yang sudah berkecimpung di dunia persalonan lebih dari 20 tahun dan beberapa pejabat di Salon XYZ, diantaranya: Ibu Tini Martini selaku pemilik sekaligus direktur utama; Bapak Drs Untung Margiono MS selaku direktur operasional; Bapak Ir. I nyoman Darka SE selaku direktur keuangan. Selanjutnya, wawancara pihak eksternal dilakukan dengan beberapa konsumen Salon XYZ, antara lain: Ny. Ani Pudjoningsih, konsumen Salon XYZ cabang Bangbarung; Nn. Arimbi, konsumen Salon XYZ cabang Tajur; Nn. Ririn Alfarary, konsumen Salon XYZ cabang Bogor Baru.

Identifikasi pengelolaan bisnis Salon XYZ dilakukan menggunakan analisis deskriptif. Analisis ini bertujuan mendeskripsikan suatu keadaan, peristiwa, objek, apakah orang atau segala sesuatu yang terkait dengan variabel-variabel yang bisa dijelaskan baik dengan angka-angka maupun dengan kata-kata (Punaji, 2010). Menurut Davenport (2013) aktivitas yang terukur dan terstruktur untuk memproduksi output tertentu untuk kalangan pelanggan tertentu. Terdapat di dalamnya penekanan yang kuat pada "bagaimana" pekerjaan itu dijalankan di suatu organisasi, tidak seperti fokus dari produk yang berfokus pada aspek "apa". Suatu proses merupakan urutan spesifik dari aktivitas kerja lintas waktu dan ruang, dengan suatu awalan dan akhiran, dan secara jelas mendefinisikan input dan output. Karakteristik yang dianggap harus dimiliki suatu proses bisnis adalah Definitif (proses bisnis harus memiliki batasan, masukan serta keluaran yang jelas); Urutan (proses bisnis harus terdiri dari aktivitas yang berurut sesuai waktu dan ruang); Pelanggan (proses bisnis harus mempunyai penerima hasil proses); Nilai tambah (transformasi yang terjadi harus memberikan nilai tambahpada penerima); Keterkaitan (suatu proses tidak dapat berdiri sendiri, melainkan harus terkait dalam suatu struktur organisasi); Fungsi silang (suatu proses umumnya mencakup beberapa fungsi).

Untuk mengetahui faktor kekuatan dan kelemahan internal menggunakan analisis IFE (Internal Factor Evaluation). Faktor peluang dan ancaman perusahaan dianalisis menggunakan EFE (External Factor Evaluation). Masalah tersebut penting karena faktor eksternal perusahaan berpengaruh secara langsung maupun tidak langsung terhadap kinerja perusahaan. Selanjutnya hasil dari IFE EFE akan dimasukkan ke kuadaran pada matriks IE. Analisis IE merupakan analisis penggabungan dari faktor internal dan eksternal. Parameter yang digunakan meliputi kekuatan internal perusahaan dan pengaruh eksternal yang dihadapi. Menurut Raymond et al. (2012) matriks IE merupakan alat perumusan strategi meringkas dan mengevaluasi kekuatan dan kelemahan utama dalamarea fungsional bisnis, dan juga menjadi landasanuntuk mengidentifikasi serta mengevaluasi hubungan di antara area tersebut.

Perumusan alternatif strategi menggunakan matriks SWOT. Matriks ini menggambarkan secara jelas bagian peluang dan ancaman eksternal yang dihadapi disesuaikan dengan kekuatan dan kelemahan yang dimiliki. Tahap selanjutnya adalah mengembangkan alternatif strategi dengan melakukan perbandingan berpasangan. Matriks SWOT dapat membantu dalam melakukan perbandingan berpasangan antara kekuatan dan peluang (SO Strategy), kekuatan dan ancaman (ST Strategy), peluang dan kelemahan (WO Strategy) dan antara kelemahan dan ancaman (WT Strategy). Setelah didapatkan alternatif strategi dari matriks SWOT, penentuan prioritas trategi akan dilakukan dengan menggunakan Quantitative Strategic Planning Matrix (QSPM) adalah alat yang direkomendasikan untuk melakukan evaluasi pilihan strategi alternatif secara objektif berdasarkan faktor kunci sukses internal eksternal yang telah diidentifikasi sebelumnya. Matriks QSPM bertujuan menentukan pemilihan strategi yang terbaik dalam hal memutuskan strategi apa yang akan dijalankan oleh perusahaan pada jangka pendek dan jangka panjang (Isnandar et al. 2016). Adapaun kerangka pemikiran penelitian dapat dilihat pada Gambar 2. 


\section{HASIL}

\section{Deskripsi Proses Bisnis Salon XYZ}

Dasar keinginan wanita yang ingin terlihat selalu cantik dan menarik menjadikan salon tempat yang menyenangkan. Dengan 11 outlet Salon XYZ memudahkan para customer datang ke salon. Bagi konsumen yang setiap minggu datang, biasanya mereka sudah memiliki jadwal perawatan mingguan yang akan dicatat oleh petugas customer service dan tamu tersebut tinggal datang pada hari yang dijadwalkan. Bagi tamu yang lain, kemudahan untuk perawatan bisa dilakukan booking melalui telepon, hal ini memberikan kemudahan sehingga customer tidak perlu antri lama untuk mendapat giliran perawatan.

Setiap wanita menginginkan perawatan dan menilai kecantikannya dari aspek yang berbeda. Customer yang menginginkan rambut sehat dan rapi akan melakukan perawatan creambath, hairspa, potong dan pewarnaan rambut. Konsumen yang menilai kecantikan dan peduli akan kebersihan wajahnya akan memilih untuk melakukan perawatan facial wajah, masker, setrika wajah, totok aura, sedangkan konsumen yang menilai kecantikan dari kebersihan tubuh mereka akan melakukan perawatan lulur, sauna, mandi susu hingga menicure, pedicure. Perawatan yang paling banyak diminati adalah perawatan lulur, hairspa dan manicure pedicure. Menurut salah satu responden, lulur dan hairspa di Salon XYZ memberikan relaksasi pada tubuhnya. Banyak konsumen booking terlebih dahulu untuk menghindari antrian. Pada waktu yang disepakati customer akan datang dan dipersilahkan menunggu, sekitar 5-10 menit berselang customer akan disapa oleh terapisnya dan dipersilahkan untuk memulai perawatan lulur. Perawatan lulur membutuhkan waktu 2,5 jam yang meliputi pemijatan, scrub badan, sauna dan mandi. Konsumen mendapatkan relaksasi, kelancaran peredaran darah, kebersihan tubuh, kulit yang cerah dan juga dapat membersihkan pori-pori kulit. Proses hairspa membutuhkan waktu 2 jam meliputi pencucian rambut, pemijatan kepala menggunakan cream beraroma relaksasi dengan beberapa pilihan, steam rambut, pencucian rambut, penggunaan hair tonic dan terakhir akan di keringkan dan di blow sesuai dengan keinginan konsumen. Dalam waktu 2 jam konsumen mendapatkan relaksasi, revitalisasi rambut dan rambut yang tersisir rapi. Konsumen akan keluar dari salon dalam kondisi badan segar dan rileks.

Outlet bertugas memberikan perawatan terbaik ke tamu dibantu oleh supporting system, dengan adanya beberapa divisi membuat perusahaan dapat menjalankan kegiatan operasionalnya. Divisi general affair (GA) merupakan divisi tersibuk di perusahaan. GA bertugas mengadakan material yang akan digunakan konsumen perawatan. GA berhubungan langsung dengan para pemasok bahan baku.

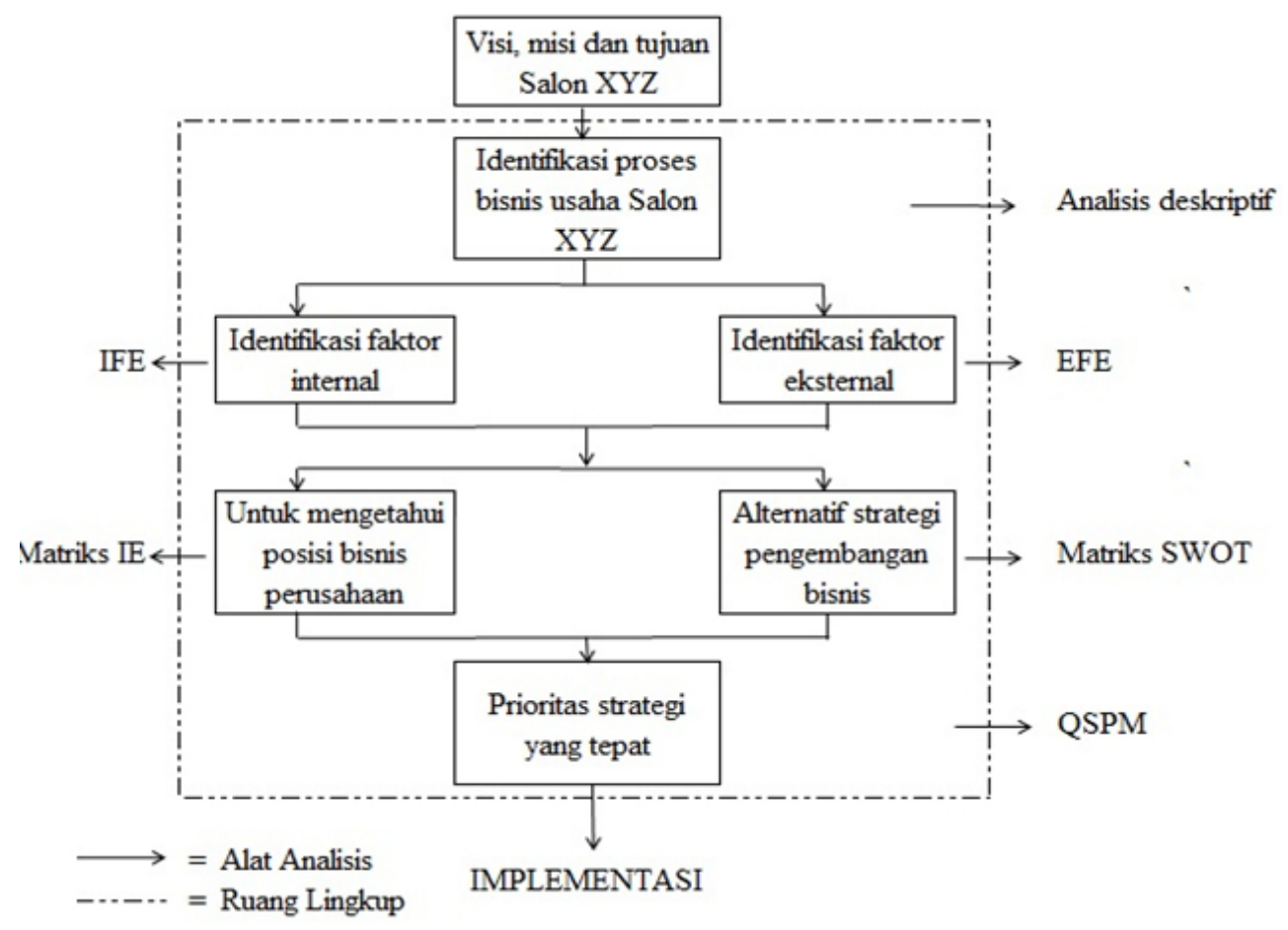

Gambar 2. Kerangka pemikiran penelitian 
Divisi training sangat berperan penting untuk memberikan skill pada terapis yang akan memberikan service customer. Setiap karyawan yang baru direkrut akan di training selama 1 bulan. Setelah itu akan dilakukan penempatan ke cabang. Selain mentraining karyawan baru, divisi ini bertugas memperbaiki, mengingatkan danmemantapkan skill karyawan. Setiap karyawan baru dan karyawan senior akan mendapatkan pengajaran yang berkelanjutan. Pengajaran berupa skill bidang persalonan akan diajarkan mulai dari perawatan kepala hingga perawatan kaki. Divisi ini bertanggung jawab terhadap karyawan yang kena complain karena tidak menjalankan SOP ataupun karyawan yang bekerja tidak berkualitas.

Pemeliharaan 13 gedung ditangani oleh divisi maintenance. Alat-alat elektronik dipakai berjam-jam membuat alat-alat yang terdapat di outlet menjadi lebih cepat rusak dari masa hidup yang seharusnya. Dengan adanya divisi maintenance kerusakan dapat ditanggulangi sehingga dapat memberikan kenyamanan perawatan pada customer. Kepala maintenance membawahi ahli elektrik, ahli bangunandan ahli alatalat elektronik.

Divisi HRD (Human Resource Development) bertugas untuk mengatur serta mengembangkan sumberdaya seluruh karyawan. HRD bertanggung jawabdalam proses rekrutmentenaga kerja, dari mencari kandidat terbaik, melakukan sesi wawancara, sampai proses seleksi. Menurut Sheehan (2012) strategi peningkatan kapasitas SDM merupakan strategi yang penting dalam perumusan strateg perusahaan kedepannya, dikarenakan peningkatan kapasitas karyawan berkorelasi positif terhadap daya saing perusahaan. Tahun 2017 , turn over lebih dari $25 \%$. Penyebabnya tingginya adalah karyawan dibajak oleh kompetitor. Sudah terbentuknya skill bidang persalonan yang dimiliki karyawan perusahaan menyebabkan kompetitor berlomba menarik para karyawan untuk berpindah tempat bekerja. Dengan berkurangnya karyawan berarti menambah pekerjaan baru bagi perusahaan terutama bagi divisi HRD dan training. Divisi tersebut harus dapat merekrut dan mencetak karyawan baru yang berkualitas. Namun, tidak mudah untuk dapat mencetak karyawan yang kompeten dalam bidang persalonan, terlebih lagi dengan tingkat pendidikan yang kurang.

Menurut Jusuf (2010) loyalitas merupakan suatu sikap yang timbul sebagai akibat keinginan untuk setia dan berbaikti pada pekerjaan,kelompok, atasan maupun pada tempat kerjanya. Ciri-ciri loyalitas menurut Poerwopoespito et al. (2000) antara lain: jujur; memiliki rasa memiliki perusahaan sehingga bersama-sama menjaga perusahaan; mengerti kesulitan perusahaan; bekerja giat; menciptakan suasana yang menyenangkan di perusahaan; menyimpan rahasia perusahaan; menjaga dan meninggikan citra perusahaan; hemat; tidak apriori terhadap perubahan.

\section{Identifikasi Faktor Internal}

Dari hasil analisis matriks IFE diketahui bahwa faktor yang menjadi kekuatan utama perusahaan adalah perusahaan memiliki SOP dengan skor sebesar 0,51 dan kelemahan utama perusahaan, yaitu turn over karyawan dengan skor sebesar 0,12 . Total skor faktor internal adalah 2,74 yang berarti Salon XYZ memiliki kondisi internal yang sedang. Hasil matriks IFE selengkapnya pada Tabel 1 .

Tabel 1. Hasil matriks IFE

\begin{tabular}{|c|c|c|c|c|}
\hline Kekuatan & Bobot & Rating & Skor & Ranking \\
\hline Memiliki training centre & 0,12 & 4 & 0,48 & 2 \\
\hline Memiliki SOP & 0,13 & 4 & 0,51 & 1 \\
\hline Varian perawatan yang banyak & 0,11 & 3 & 0,37 & 4 \\
\hline Elemen supporting yang kuat & 0,10 & 4 & 0,38 & 3 \\
\hline Memiliki banyak outlet di kota Bogor & 0,09 & 3 & 0,27 & 5 \\
\hline \multicolumn{5}{|l|}{ Kelemahan } \\
\hline Pendidikan karyawan yang rendah & 0,10 & 2 & 0,17 & 5 \\
\hline Belum memakai alat dengan teknologi terkini & 0,10 & 2 & 0,17 & 4 \\
\hline Belum ada divisi marketing & 0,08 & 2 & 0,13 & 2 \\
\hline Belum ada outlet di luar kota Bogor & 0,08 & 2 & 0,14 & 3 \\
\hline Turn over karyawan yang tinggi & 0,09 & 1 & 0,12 & 1 \\
\hline Total & 1 & & 2,74 & \\
\hline
\end{tabular}




\section{Identifikasi Faktor Eksternal}

Dari hasil analisis matriks EFE dapat diketahui bahwa faktor yang menjadi peluang utama dengan skor 0,43 adalah customer yang mencari salon khusus wanita untuk kenyamanan dan faktor yang menjadi ancaman utama adalah sering mati listrik dan air dengan skor 0,46. Total skor faktor eksternal 3,28 yang berarti respon Salon XYZ terhadap peluang dan ancaman dikategorikan sudah di atas rata-rata. Hasil matriks EFE selengkapnya pada Tabel 2.

\section{Matriks Internal-Ekstrnal (IE)}

Hasil matriks IFE dan EFE, diketahui posisi perusahaan pada kuadran II dengan posisi grow and build (Gambar 3). Menurut David (2012) strategi yang termasuk grow and build adalah strategi intensif seperti penetrasi pasar, pengembangan pasar, pengembangakan produk, integrasi kebelakang, integrasi kedepan, dan integrasi horizontal.

Tabel 2. Hasil matriks EFE

\begin{tabular}{lcccc}
\hline Peluang & Bobot & Rating & Skor & Ranking \\
\hline Meningkatnya segmen pasar menengah ke atas & 0,10 & 4 & 0,41 & 3 \\
Sikap customer yang mencari salon khusus wanita untuk kenyamanan & 0,11 & 4 & 0,43 & 1 \\
Ada kecenderungan kebutuhan salon di luar Bogor & 0,12 & 3 & 0,41 & 2 \\
Permintaan franchise yang tinggi & 0,08 & 4 & 0,29 & 4 \\
Peningkatan angkatan kerja yang belum mendapatkan kerja & 0,09 & 3 & 0,29 & 5 \\
\hline Ancaman & & & & \\
\hline Karyawan dibajak oleh salon lain & 0,11 & 4 & 0,39 & 2 \\
Kompetitor memakai peralatan yang canggih & 0,09 & 3 & 0,25 & 3 \\
Banyak munculnya salon baru di sekitar Salon XYZ & 0,09 & 2 & 0,18 & 4 \\
Sering mati listrik dan air & 0,13 & 4 & 0,46 & 1 \\
Kelangkaan bahan baku pada waktu tertentu & 0,09 & 2 & 0,17 & 5 \\
\hline \multicolumn{1}{c}{ Total } & 1 & & 3,28 & \\
\hline
\end{tabular}

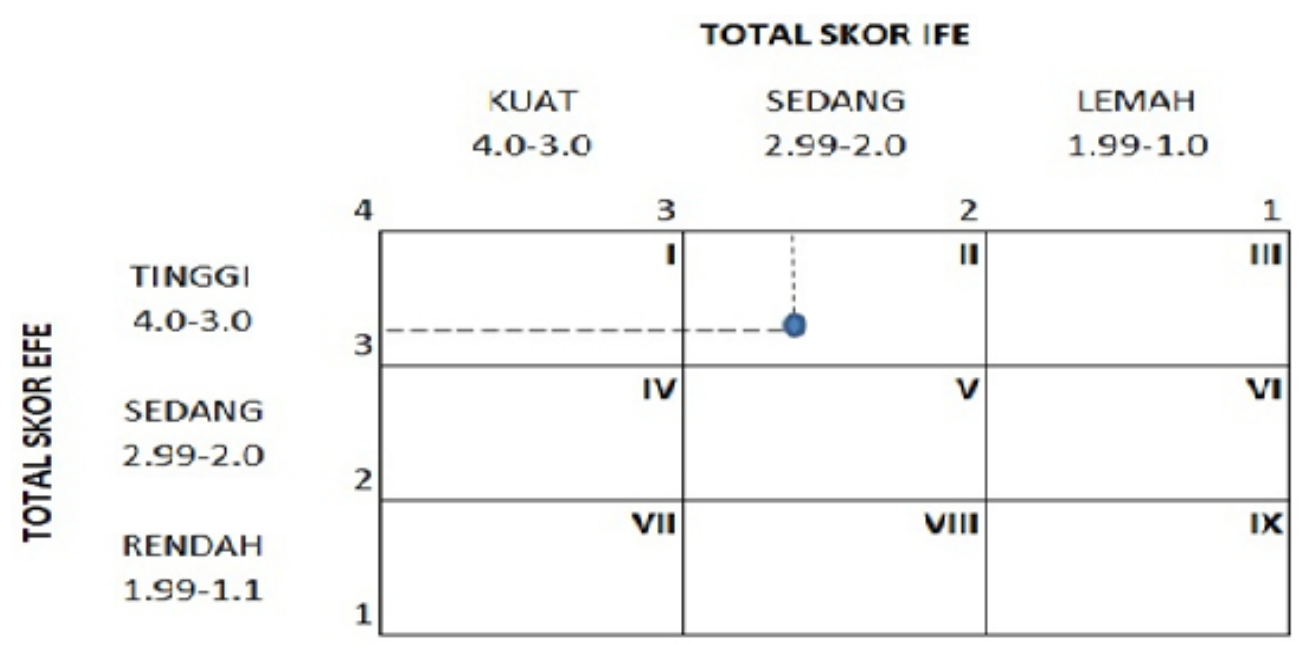

Gambar 3. Matriks IE Salon XYZ 


\section{Matriks SWOT}

\section{Strategi S-O}

Strategi ini dibuat berdasarkan jalan pikiran perusahaan, yaitu dengan memanfaatkan seluruh kekuatan untuk merebut dan memanfaatkan peluang sebesar-besarnya. Strategi SO menggunakan kekuatan internal perusahaan untuk memanfaatkan peluang eksternal. Pada matriks SWOT diatas terdapat strategi SO, yaitu memperluas pasar dengan membuka di luar kota Bogor, hal ini dengan menggunakan kekuatan Salon XYZ seperti S1(memiliki training centre), S2 (memiliki SOP), S3 (varian perawatan yang banyak) dan S4 (elemen supporting yang kuat); untuk meraih peluang, yaitu O1(meningkatnya segmen pasar menengah ke atas), O2 (sikap customer yang mencari salon khusus wanita untuk kenyamanan), $\mathrm{O} 3$ (ada kecenderungan kebutuhan salon di luar Bogor), O4 (permintaan franchise yang tinggi), O5 (peningkatan angkatan kerja yang belum mendapatkan kerja). Selanjutnya, meningkatkan kerjasama dan kemitraan, strategi ini juga memanfaatkan kekuatan internal Salon XYZ yaitu S1(memiliki training centre), S2 (memiliki SOP), S3 (varian perawatan yang banyak) dan S4 (elemen supporting yang kuat untuk meraih peluang) O3 (ada kecenderungan kebutuhan salon di luar Bogor), O4 (permintaan franchise yang tinggi).

\section{Strategi S-T}

Strategi ini menggunakan kekuatan yang dimiliki perusahaan untuk mengatasi ancaman. Strategi ST menggunakan kekuatan internal perusahaan untuk menghindari atau mengurangi dampak ancaman eksternal.PadamatriksSWOTdiatas terdapatstrategiST, yaitu meningkatkan daya saing dengan meningkatkan kualitas pelayanan, melalui pemanfaatkan kekuatan internal Salon XYZ, S1 (memiliki training centre), S2 (memiliki SOP), S3 (varian perawatan yang banyak) dan S4 (elemen supporting yang kuat), S5 (memiliki banyak outlet di kota Bogor untuk mengatasi ancaman), T2 (kompetitor memakai peralatan yang canggih), T3 (banyak munculnya salon baru disekitar Salon XYZ). Selanjutnya, meningkatkan sarana perawatan melalui pemanfaatkan kekuatan internal Salon XYZ, yaitu S4 (elemen supporting yang kuat), untuk mengatasi ancaman T2 (kompetitor memakai peralatan yang canggih), T3 (banyak munculnya salon baru disekitar Salon XYZ), T4 (sering mati listrik dan air) dan T5 (kelangkaan bahan baku pada waktu tertentu).

\section{Strategi W-O}

Strategiini diterapkanberdasarkanpemanfaatan peluang yang ada dengan cara meminimalkan kelemahan yang ada. Strategi WO bertujuan memperbaiki kelemahan internal dengan memanfaatkan peluang eksternal. Pada matriks SWOT diatas terdapat strategi WO, yaitu membentuk divisi marketing. stategi ini memanfaatkan kelemahan internal perusahaan yaitu W2 (belum memakai alat dengan teknologi canggih W3): belum ada divisi marketing dan W4 (belum ada outlet di luar kota Bogor) untuk meraih peluang O1 (meningkatnya segmen pasar menengah ke atas), O2 (sikap customer yang mencari salon khusus wanita untuk kenyamanan), O3 (ada kecenderungan kebutuhan salon di luar Bogor), O4 (permintaan franchise yang tinggi).

\section{Strategi W-T}

Strategi ini didasarkan pada kegiatan yang bersifat defensif dan berusaha meminimalkan kelemahan serta menghindari ancaman. Strategi WT bertujuan mengurangi kelemahan internal dengan menghindari ancaman eksternal. Pada matriks SWOT diatas terdapat strategi WT, yaitu merekrut karyawan dengan tingkat pendidikan tertentu dan melatih tenaga kerja dengan meminimalkan kelemahan W1(pendidikan karyawan yang rendah), W5 (turn over karyawan yang tinggi) untuk menghidari ancaman T1(karyawan dibajak oleh salon lain), T2 (kompetitor memakai peralatan yang canggih), T3 (banyak munculnya salon baru di sekitar Salon XYZ). Selanjutnya, memakai sistem kontrak dengan karyawan, dengan melihat kelemahan W5 (turn over karyawan yang tinggi) untuk menghidari ancaman T1(karyawan dibajak oleh salon lain). Di samping itu, mengggunakan alat teknologi terkini, dengan melihat kelemahan W2 (belum memakai alat dengan teknologi terkini) untuk menghindari ancaman T2 (kompetitor memakai peralatan yang canggih).

\section{Analisis Matriks QSPM}

Berdasarkan matriks QSPM, diperoleh urutan dari nilai TAS dari tertinggi hingga terrendah, yaitu sebagai berikut:

1) Memperluas pasar dengan membuka di luar kota Bogor dengan nilai, yakni 7,33.

2) Meningkatkan kerja sama dan kemitraan mempunyai dengan nilai 7,04

3) Membentuk divisi marketing berada dalam prioritas ketiga dengan nilai 6,59 . 
4) Meningkatkan daya saing dengan meningkatkan kualitas pelayanan. Strategi ini memiliki skor sebesar 5,46.

5) Meningkatkan sarana perawatan dengan nilai sebesar 5,28.

6) Merekrut karyawan dengan tingkat pendidikan tertentu dan melatih tenaga kerja. dengan nilai 5,10 .

7) Memakai sistem kontrak dengan karyawan dengan nilai sebesar 5,00.

Selanjutnya disesuaikan antara strategi dari matriks IE dengan strategi QSPM. Adapun Strategi Grow and build dan strategi QSPM selengkapanya pada Tabel 3.

\section{Implikasi Manajerial}

Rekomendasi strategi prioritas yang disarankan dilakukan oleh perusahaan, yang pertama adalah membentuk divisi marketing dengan merekrut SDM bagian marketing dan membentuk program promosi. Divisi marketing harus mempertahankan customer Salon XYZ dan mendatangkan konsumen baru. Hal tersebut bisa segera dilakukan karena tidak memerlukan dana.
Strategi kedua adalah perluasan pasar ke luar kota Bogor dengan kerjasama kemitraan. Demi mencapai misi Salon XYZ untuk tumbuh secara nasional Salon XYZ harus berani untuk mengembangkan pasar ke kota besar. Kota Bandung disarankan menjadi target perluasan pasar selanjutnya dikarenakan Bandung merupakan kota pendidikan dan kota wisata dengan populasi wanita sebesar 1.233.446 (BPS, 2017) dan ada 57 perguruan tinggi yang tersebar di Bandung. Itu mengindikasikan banyak pendatang dari luar kota Bandung yang mengenyam pendidikan disana. Dua strategi diatas diutamakan karena pembentukan divisi yang akan melakukan program-program promosi dan perluasan pasar dengan kerjasama kemitraan akan dengan cepat menaikkan pendapatan perusahaan sehingga pendapatan tersebut bisa digunakan untuk untuk melakukan strategi lain yang membutuhkan dana. Strategi ini akan meningkatkan omzet perusahaan.

Strategi prioritas ketiga yang disarankan adalah merekrut karyawan dengan tingkat pendidikan tertentu dan mengadakan pelatihan. Dengan naiknya standar pendidikan akan membawa dampak baik bagi peningkatan kualitas perawatan yang secara otomatis akan membuat konsumen puas.

Tabel 3. Strategi grow and build dan strategi QSPM

\begin{tabular}{|c|c|c|}
\hline Strategi grow and build & Prioritas strategi & Hal yang harus dilakukan \\
\hline \multirow[t]{3}{*}{ 1. Perluasan pasar } & $\begin{array}{l}\text { Memperluas pasar dengan membuka } \\
\text { outlet diluar kota Bogor dengan } \\
\text { kerjasama kemitraan }\end{array}$ & $\begin{array}{l}\text { Mempertimbangkan Salon XYZ sebagai bisnis } \\
\text { waralaba }\end{array}$ \\
\hline & $\begin{array}{l}\text { Memakai sistem kontrak dengan } \\
\text { karyawan }\end{array}$ & $\begin{array}{l}\text { Membuka outlet di luar kota Bogor yang } \\
\text { mempunyai demand tinggi terhadap salon }\end{array}$ \\
\hline & & Membuat kontrak kerja dengan karyawan \\
\hline \multirow[t]{2}{*}{ 2. Penetrasi pasar } & Membentuk divisi marketing & $\begin{array}{l}\text { Melakukan promosi media cetak dan media } \\
\text { elektronik }\end{array}$ \\
\hline & $\begin{array}{l}\text { Meningkatkan daya saing dengan } \\
\text { meningkatkan kualitas pelayanan }\end{array}$ & Memaksimalkan kerja elemen support \\
\hline \multirow[t]{7}{*}{ 3. Perluasan produk } & Melengkapi sarana perawatan & $\begin{array}{l}\text { Perencanaan pembelian sarana perawatan secara } \\
\text { berkala }\end{array}$ \\
\hline & Menggunakan alat teknologi terkini & Pembuatan sumur di setiap cabang \\
\hline & $\begin{array}{l}\text { Merekrut karyawan dengan tingkat } \\
\text { pendidikan tertentu dan melatih } \\
\text { tenaga kerja }\end{array}$ & Peningkatan kapasitas genset \\
\hline & & Penambahan varian produk \\
\hline & & $\begin{array}{l}\text { Perencanaan pembelian alat teknologi terkini } \\
\text { secara berkala }\end{array}$ \\
\hline & & $\begin{array}{l}\text { Menaikkan standar pendidikan dalam perekrutan } \\
\text { karyawan }\end{array}$ \\
\hline & & Lebih sering mengadakan pelatihan \\
\hline
\end{tabular}


Strategi prioritas keempat adalah melengkapi sarana perawatan. Dengan melakukan 2 tahapan. Tahapan pertama yang dilakukan adalah penambahan varian produk dilakukan 3 kali dalam setahun. Hal ini dilakukan untuk menghindari kejenuhan pada konsumen dan memenuhi kebutuhan konsumen. Tahapan kedua akan dilakukan pembuatan 2 sumur setiap bulan. Pembelian genset dimulai bulan selanjutnya setelah beres pengerjaan sumur. Pembelian akan dilakukan 1 bulan sekali. Dengan melengkapi sarana perawatan seperti genset dan sumur diharapkan akan mengatasi masalah mati air dan listrik membawa keuntungan bagi perusahaan yang dapat menekan biaya operasional saat terjadi mati listrik atau mati air serta berkurangnya complaint dari konsumen terkait listrik dan air.

Empat strategi prioritas diatas, diharapkan perusahaan dapat menanggulangi permasalahan yang ada, menanggulangi faktor kelemahan internal dan juga ancaman eksternal. untuk menanggulangi faktor kelemahan utama, yaitu turn over karyawan yang tinggi, sejalan dengan melakukan perekrutan karyawan dengan pendidikan tertentu sehingga masalah kekurangan pegawai akan teratasi. Untuk mengatasi seringnya mati air dan listrik sebagai ancaman utama, maka strategi peningkatan sarana perawatan dinilai dapat menjadi jalan keluar ancaman tersebut dan untuk mengatasi omzet yang menurun dan mengatasi kelemahan peringkat 2, yaitu belum ada divisi marketing.

Manajemen perusahaan melihat beberapa peluang integrasi ke depan dan integrasi ke belakang yang dapat dijalakan. Disarankan perusahaan menjalankan strategi integrasi ke depan terlebih dahulu. Membuka bisnis tata rias pengantin mempunyai pasar yang menjanjikan. Dari data Bappeda Bogor (2017), data pernikahan dan pembuatan akta pernikahan memiliki angka tang cukup tinggi. Data tahun 2014 perkawinan sebanyak 469 pasangan menikah, tahun 2015 terdapat 494 pasangan menikah, tahun 2016 sebanyak 511 pasangan yang menikah dan pada tahun 2017 terdapat 423 pasangan menikah. Disamping tingginya demand, tata rias pengantin tidak membutuhkan investasi yang besar, juga tidak membutuhkan investasi properti. Tata rias pengantin ini dapat di buka di Salon XYZ outlet Bangbarung karena mempunya luas bangunan dibanding dengan outlet lainnya.Untuk integrasi ke belakang perusahaan tidak disarankan membuka pabrik bahan baku, mengingat nilai investasi yang besar dan saat ini perusahaan sedang melakukan diversifikasi usaha sehingga belum mempunyai dana yang leluasa untuk digunakan.

\section{KESIMPULAN DAN SARAN}

\section{Kesimpulan}

Hasil penelitian yang dilakukan terhadap Salon XYZ, diketahui bahwa 1) setiap wanita menginginkan perawatan dan menilai kecantikannya dari aspek yang berbeda. Ada yang memilih perawatan rambut, wajah, tubuh ataupun perawatan tangan dan kaki. Peawatan yang paling banyak diminati adalah lulur, hairspa, manicure dan pedicure. Setelah perawatan konsumen akan merasa rileks, bersih dan cantik. Operasional salon untuk memberikan perawatan yang memuaskan bagi customer dibantu oleh supporting system. Hasil analisis internal menggunakan IFE diperoleh skor sebesar 2,74 dan hasil analisis eksternal dengan menggunakan EFE diperoleh skor sebesar 3,28. Berdasarkan matriks IE posisi perusahan berada pada kuadran II yaitu pada posisi bertumbuh dan membangun. Strategi yang dapat dilakukan adalah strategi intensif dengan melakukan penetrasi pasar, perluasan pasar dan perluasan produk. Selanjutnya, hasil formulasi alternatif strategi dari matriks SWOT didapatkan 8 alternatif strategi yaitu memperluas pangsa pasar dengan membuka di luar kota Bogor, meningkatkan kerjasama dan kemitraan, membentuk divisi marketing, meningkatkan daya saing dengan meningkatkan kualitas pelayanan, meningkatkan sarana perawatan, merekrut karyawan dengan tingkat pendidikan tertentu dan melatih tenaga kerja, memakai sistem kontrak dengan karyawan, dan mengggunakan alat teknologi terkini. Perumusan prioritas strategi menunjukkan bahwa strategi prioritas pertama adalah memperluas pasar dengan membuka outlet di luar kota Bogor.

\section{Saran}

Untuk penelitian selanjutnya perlu menggunakan expert opinion dari para pengusaha salon terkemuka di Indonesiaagar mendapatkan informasi yang lebih luas terkait dengan bisnis salon kecantikan dan juga perlu pengkajian implementasi strategi yang diprioritaskan seperti memperluas pasar dengan membuka outlet di luar kota misalnya dengan Focus Group Discusion (FGD). 


\section{DAFTAR PUSTAKA}

[BPS] Badan Pusat Statistik. 2005. Klasifikasi Baku Lapangan Usaha Indonesia. Revisi KBLI 2000. Jakarta: BPS.

[BPS] Badan Pusat Statistik Bandung. 2017. Jumlah populasi wanita. https://bandungkota.bps.go.id/ [25 Desember 2017].

BAPPEDA. 2017. Kota bogor dalam angka. https:// bappeda.kotabogor.go.id [20 Desember 2017].

Coulter M. 2005. Strategic Management in Action (3 ${ }^{\text {th }}$ ed). New Jersey:Pearson Prentice Hall.

Davenport T. 2013. Process Innovation: Reengineering work through information technology. Boston: Harvard Business School Press.

David FR. 2012. Manajemen Strategis. Konsep konsep. Edisi Kesembilan. Terjemahan dari Strategic Management: Concept Ninth Edition. Diterjemahkan oleh Julianto Agung S. Penerbit Indeks. Jakarta

Hidayat NC. 2012. Strategi memasarkan produk jasa. Jurnal Progresif 9(25): 114-140

Hutahaean R, Fahmi I, Yusuf AM. 2017. Perumusan strategi bisnis PT XYZ. Jurnal Aplikasi Bisnis Manjemen 3 (3): 448-457. https://doi. org/10.17358/jabm.3.3.447.

Isnandar FR, Firdaus M, Maulana A. 2016. Strategi peningkatan aset PT BPR Syariah Harta Insan Karimah (HIK) Ciledug. Jurnal Aplikasi Bisnis dan Manajemen 2(1):12-22.

Jusuf H. 2010. Tingkatkan loyalitas guna peningkatan prestasi kerja dan karir. https://www.slideserve. com/aquila-merrill/tingkatkan-loyalitas-gunapeningkatan-prestasi-kerja-dan-karir-oleh-drshusain-jusuf-m-pd [20 Desember 2017].

Karnelly O. 2010. Hubungan antara pemasaran jasa, kepuasan, dan loyalitas konsumen. Jurnal Aplikasi Bisnis 1(1): 48-58.

Klick J, Stratmann T. 2008. Do Spa Visit Improve Health: evidence from german micro data. Eastern Economic Journal 8(34): 364 - 374. https://doi.org/10.1057/palgrave.eej.9050038.

Komaryatin N. 2007. Strategi pemasaran dengan pendekatan SWOT. Jurnal Dinamika Ekonomi dan Bisnis 4(1): 85-100.

Kurniawati T, Sari KBDK. 2009. Analisis dan pilihan Strategi: membangun eksistensi perusahaan di masa kritis. Journal Ekonomi Bisnis 14(3): 179190.
Kompas. 2012. Jumlah salon 100.000, pasar salon RI capai 16,6 triliun. http//bisniskeuangankompas. com [10 November 2017].

Mitrady I, Daryanto HK, Maulana A. 2015. Loan distribution strategy PT. Bank X (Persero), Tbk-Bogor credit business unit.Jurnal Aplikasi Bisnis dan Manajemen 1(2): 98-107. https://doi. org/10.17358/JABM.1.2.98.

Nawab S, Bhatti KK, Shafi K. 2011. Effect of motivation on employees performance. Interdisciplinary Journal of Contemporary Research in Business 2(3):1209-1216

Poerwopoespito, Oerip S dan Tatag Utomo. 2000. Mengatasi Krisis Manusia Di Perusahaan (Solusi Melalui Pengembangan Sikap Mental). Jakarta: Gramedia Widiasarana Indonesia

Punaji S. 2010. Metode Penelitian Pendidikan dan Pengembangan. Jakarta: Kencana.

Raymond MLB, Ine M, Iwang G.2012.Analisis pengembangan usaha pemindangan ikan di Kecamatan bekasi Barat. Jurnal Perikanan dan Kelautan 3(1):17-24.

Rurkinantia A, Oktaviani R, Sanim B. 2017. Strategi pengembangan bisnis pemotongan sapi. Jurnal Aplikasi Bisnis dan Manajemen 3 (3): 353-360

Sheehan NT. 2012.A risk-based approach to strategy execution.Journal of Business Strategy 29(3): 25-34.

Tabassi AA, Ramli M, Bakar AHA. 2012. Effects of training and motivation practices on teamwork improvement and task efficiency: the case of construction firms. International Journal of Project Management 30(2):213-224. https://doi. org/10.1016/j.ijproman.2011.05.009.

Tantra D, Kendengis Y, Santoso LW. 2015. Perencanaan strategis sistem informasi pada perusahaan jasa ekspedisi PT. X. Jurnal Infra 3(1):1-8.

Turere VN. 2013. Pengaruh pendidikan dan pelatihan terhadap peningkatan kinerja karyawan pada Balai Pelatihan Teknis Pertanian Kalasey. Jurnal Riset Ekonomi, Manajemen, Bisinis dan Akutansi 1(3): 10-19.

Widjaja B. 2009. Lifestyle Marketing (Paradigma Baru Pemasaran Bisnis Jasa dan Lifestyle). Jakarta: Gramedis Pustaka Utama.

Winarno FG, Agustinah W. 2007. Herba dan Rempah Bagi Pengobatan, Kosmetika dan Spa. Bogor: M-BRIO PRESS. 
Xia Chan. 2011. A SWOT study of the development strategy of haier group as one of the most successful chinese enterprises. International Jurnal of Business and Social Science 2(11): 147-153.
Zuhaidha SA, Santoso S, Maesaroh M. 2014. Perencanaan strategi pengembangan ruang terbuka hijau Kota Semarang (studi kasus: Hutan Wisata Tinjomoyo). Journal of Public Policy and Management Review 3(2): 390-399. 